\title{
STUDI PERENCANAAN ALUR KAPAL DI BELOKAN SUNGAI KAHAYAN KOTA PALANGKA RAYA
}

\author{
Amelda Eva Adelina ${ }^{1}$, Nomeritae ${ }^{2}$, Hendro Suyanto ${ }^{3}$ \\ ${ }^{123}$ Program Studi Teknik Sipil, Fakultas Teknik, Universitas Palangka Raya \\ E-mail: radenamelda@gmail.com ${ }^{1}$, nomeritae@jts.upr.ac.id ${ }^{2}$, \\ hendrosuyanto@yahoo.co.id ${ }^{3} /$ HP.+62895700413941 ${ }^{1}$
}

\begin{abstract}
ABSTRAK
Gerusan dan sedimentasi seringkali terjadi pada penggal tertentu Sungai Kahayan yang berada di sekitar belokan. Hal tersebut disebabkan karena kecepatan aliran pada belokan yang cenderung tidak stabil. Kondisi tersebut tentu akan mempengaruhi alur pelayaran sungai yang digunakan oleh masyarakat untuk berbagai aktivitas. Penggal Sungai Kahayan yang diteliti adalah penggal Muara Rungan hingga Hantasan Kudung. Penelitian ini bertujuan untuk: (1) mengidentifikasi kondisi arus dan sedimentasi pada lokasi penelitian, (2) memprediksi volume sedimen yang harus dikeruk sehingga mendapatkan alur pelayaran yang optimal, dan (3) mengestimasi besaran biaya yang diperlukan untuk pekerjaan pengerukan tersebut. Analisis hidrologi dilakukan untuk mendapatkan besaran debit yang diperoleh dari hasil pengukuran kecepatan dan tampang melintang sungai. Analisis hidraulika untuk memodelkan arus dan sedimentasi menggunakan perangkat lunak Surface Water Modelling System (SMS). Dari penyesuaian pemodelan Resources Management Associates-2 (RMA2) dan Two-Dimensional Sediment Transport Numerical Model (SED2D) dalam modul SMS, didapat nilai kecepatan aliran 0,192 m/detik- 0,608 m/detik yang arahnya semakin ke hilir pada sisi luar tiap belokan berpotensi terjadinya gerusan. Untuk mendapatkan alur pelayaran yang optimal bagi kapal barang dengan kapasitas 3.000 DWT beroperasi, perlu dilakukan pengerukan sedimen dengan volume sebesar 272.405,44 $\mathrm{m}^{3}$ dengan estimasi anggaran biaya $\mathrm{Rp}$. 6.709.412.678,41.
\end{abstract}

Kata kunci : sungai, alur pelayaran, SMS, RMA2, SED2D

\begin{abstract}
Scouring and sedimentation often occur in certain sections of Kahayan River at around the bend. This is due to the flow velocity at the turn tends to be unstable. This condition will certainly affect the river shipping lanes used by the community for various activities. The area of Kahayan River studied is the sections of Muara Rungan to Hantasan Kudung. This research aims to: (1) identify the flow and sedimentation conditions at the research location, (2) predict the volume of sediment that must be dredged in order to obtain an optimal shipping channel, (3) estimate the amount of costs required for the dredging work. Hydrological analysis was carried out to obtain the amount of discharge obtained from the measurement results of velocity and river cross section. Hydraulic analysis to model flow and sedimentation using Surface Water Modelling System (SMS) software. The Resources Management Associates-2 (RMA2) and TwoDimensional Sediment Transport Numerical Model (SED2D) modeling in SMS modules shows that the value of flow velocity is between $0,192 \mathrm{~m} / \mathrm{s}$ and $0,608 \mathrm{~m} / \mathrm{s}$,
\end{abstract}


as more to downstream, specifically the outside of each turn, is more likely to experience scouring. To obtain an optimal shipping channel for cargo ship with a capacity of $3.000 \mathrm{DWT}$ to operate, dredging the sedimentation needs to be done with a volume of 272,405.44 $\mathrm{m3}$ and an estimated budget cost of $R p$. 6,709,412,678.41.

Keywords: river, shipping channel, SMS, RMA2, SED2D

\section{PENDAHULUAN}

Sungai Kahayan adalah salah satu sungai terbesar di Kalimantan Tengah, dimana masyarakat di sekitar sungai memanfaatkan sungai sebagai prasarana transportasi air, pariwisata, perikanan serta perdagangan. Alat transportasi air yang digunakan untuk melakukan aktivitas di sana, terdiri dari tugboat yang membawa tongkang berisi batubara dan kayu, kapal ukuran sedang serta kapal yang digunakan warga sekitar sehari-hari yaitu kapal kecil atau klotok yang dimanfaatkan oleh nelayan untuk mencari ikan dan dijadikan kendaraan umum yang dinamakan taksi klotok (Prabowo, 2017).

Arus pada daerah belokan sungai biasanya lebih besar dan cenderung tidak stabil. Di bagian tertentu sungai akan terjadi gerusan dan sedimentasi. Pada bagian sungai yang mengalami sedimentasi akan terjadi pendangkalan sehingga perlu dilakukan pengerukan.

Penelitian Nomeritae dan Raden (2018) pada penggal Sungai Seruyan di Desa Hanau Kecamatan Hanau Kabupaten Seruyan Provinsi Kalimantan Tengah menunjukkan bahwa belokan sungai berpotensi mengalami gerusan dan defisit sedimen. Analisis kapasitas sungai serta transpor sedimen pada penelitian tersebut menggunakan Hydrologic Engineering Center-River Analysis System (HECRAS).

Untuk meningkatkan alur pelayaran yang optimal, hal-hal yang harus ditinjau yaitu kemudahan kapal berlayar dan bermanuver masuk ke area belokan Sungai Kahayan dan menganalisis pola arus serta sedimentasi di sekitar area belokan sungai tersebut. Pola arus dan sedimentasi dapat dianalisis menggunakan bantuan perangkat lunak (software), diantaranya Surface Water Modelling System (SMS).

Permasalahan yang diteliti dalam penelitian ini adalah:

1. Bagaimana kondisi arus dan sedimentasi di lokasi penelitian?

2. Berapa volume sedimen yang harus dikeruk untuk mendapatkan alur pelayaran yang optimal di lokasi penelitian?

3. Berapa biaya yang diperlukan untuk pekerjaan pengerukan di area penelitian?

Adapun tujuan penelitian adalah sebagai berikut:

1. Mengidentifikasi kondisi arus dan sedimentasi di lokasi penelitian.

2. Memprediksi volume sedimen yang harus dikeruk untuk mendapatkan alur pelayaran yang optimal di lokasi penelitian.

3. Mengestimasi biaya yang diperlukan untuk pekerjaan pengerukan di area penelitian. 


\section{TINJAUAN PUSTAKA}

\section{Karakteristik Aliran Di Belokan Sungai}

Secara alamiah alur sungai dari wilayah hulu ke hilir membentuk profil berbelokbelok akibat proses terjadinya morfodinamik sungai yang disebabkan oleh interaksi aliran, sedimen, dinding sungai dan gaya-gaya yang mempengaruhinya. Belokan-belokan sungai akan terevolusi secara terus menerus, sehingga tidak jarang dijumpai posisi-posisi belokan sungai yang tersususun seri dalam rangka mencapai keseimbangan (Maryono, 2017).

\section{Perhitungan Debit Sungai}

Debit adalah satuan besaran air yang keluar dari suatu Daerah Aliran Sungai (DAS). Debit aliran adalah laju aliran air (dalam bentuk satuan volume air) yang melewati suatu penampang melintang sungai per satuan waktu (Asdak, 2002).

Untuk mendapatkan nilai debit pada suatu periode tertentu, maka dilakukan metode dengan menggunakan persamaan sebagai berikut:

$\mathrm{Q}_{\mathrm{W}}=\mathrm{V} \times \mathrm{A}$

Keterangan:

$$
\begin{aligned}
\mathrm{Q}_{\mathrm{W}} & =\text { Debit Aliran }\left(\mathrm{m}^{3} / \text { detik }\right) \\
\mathrm{V} & =\text { Kecepatan aliran }(\mathrm{m} / \text { detik }) \\
\mathrm{A} & =\text { Luas penampang sungai }\left(\mathrm{m}^{2}\right)
\end{aligned}
$$

\section{Surface Water Modelling System (SMS)}

SMS adalah program pemodelan hidrodinamika yang dapat menghitung elevasi muka air dan kecepatan aliran untuk suatu masalah aliran pada perairan dangkal dan dapat mendukung pemodelan kondisi aliran langgeng maupun aliran tidak langgeng. SMS ini terdiri dari beberapa modul pemodelan sesuai dengan fungsinya masing-masing contohnya RMA2 dan SED2D (Syamsudin, dkk, 2017).

\section{Pemodelan Arus (RMA2)}

RMA2 adalah modul numerik elemen hingga hidrodinamis dalam bentuk dua dimensi dari rata-rata kedalaman. Persamaan kontinuitas untuk aliran dua dimensi rata-rata kedalaman (averaged continuity equation) dapat dituliskan sebagai berikut:

$\frac{\partial \mathrm{h}}{\partial \mathrm{t}}+\mathrm{h}\left(\frac{\partial \mathrm{u}}{\partial \mathrm{x}}+\frac{\partial \mathrm{v}}{\partial \mathrm{y}}\right)+\mathrm{u} \frac{\partial \mathrm{h}}{\partial \mathrm{x}}+\mathrm{v} \frac{\partial \mathrm{h}}{\partial \mathrm{y}}=0$

Persamaan momentum pada arah sumbu $\mathrm{x}$ dan $\mathrm{y}$ untuk aliran dua dimensi ratarata kedalaman dapat dituliskan sebagai berikut:

Untuk aliran arah sumbu $\mathrm{x}$,

$\frac{\partial u}{\partial t}+u \frac{\partial u}{\partial x}+v \frac{\partial u}{\partial y}+g\left(\frac{\partial h}{\partial x}+\frac{\partial a_{0}}{\partial x}\right)-\frac{\varepsilon_{x x}}{\rho} \frac{\partial^{2} u}{\partial x^{2}}-\frac{\varepsilon_{x y}}{\rho} \frac{\partial^{2} u}{\partial y^{2}}+\frac{g u}{C^{2} h} \sqrt{u^{2}+v^{2}}=0$

Untuk aliran arah sumbu y, 


$$
\frac{\partial \mathrm{v}}{\partial \mathrm{t}}+\mathrm{u} \frac{\partial \mathrm{v}}{\partial \mathrm{x}}+\mathrm{v} \frac{\partial \mathrm{v}}{\partial \mathrm{y}}+\mathrm{g}\left(\frac{\partial \mathrm{h}}{\partial \mathrm{y}}+\frac{\partial \mathrm{a}_{0}}{\partial \mathrm{y}}\right)-\frac{\varepsilon_{\mathrm{xx}}}{\rho} \frac{\partial^{2} \mathrm{v}}{\partial \mathrm{x}^{2}}-\frac{\varepsilon_{\mathrm{yx}}}{\rho} \frac{\partial^{2} \mathrm{v}}{\partial \mathrm{x}^{2}}-\frac{\varepsilon_{\mathrm{yy}}}{\rho} \frac{\partial^{2} \mathrm{v}}{\partial \mathrm{y}^{2}}+\frac{\mathrm{gv}}{\mathrm{C}^{2} \mathrm{~h}} \sqrt{\mathrm{u}^{2}+\mathrm{v}^{2}}=
$$

\section{Keterangan:}

$\begin{array}{lll}\mathrm{u} & = & \text { Kecepatan horizontal aliran arah } \mathrm{x}(\mathrm{m} / \mathrm{detik}) \\ \mathrm{v} & = & \text { Kecepatan horizontal aliran arah } \mathrm{y}(\mathrm{m} / \text { detik }) \\ \mathrm{t} & = & \text { Fungsi waktu (detik) } \\ \mathrm{g} & = & \text { Percepatan gravitasi }\left(\mathrm{m} / \text { detik }^{2}\right) \\ \mathrm{h} & = & \text { Kedalaman air }(\mathrm{m}) \\ \mathrm{ao} & = & \text { Elevasi dari dasar tampang }(\mathrm{m}) \\ \rho & = & \text { Massa jenis }\left(\mathrm{kg} / \mathrm{m}^{3}\right) \\ \varepsilon \mathrm{xx} & = & \text { Koefisien pertukaran turbulensi normal arah } \mathrm{x} \\ \varepsilon y \mathrm{x} & = & \text { Koefisien pertukaran turbulensi tangensial arah } \mathrm{x} \\ \varepsilon y \mathrm{y} & = & \text { Koefisien pertukaran turbulensi normal arah y } \\ \mathrm{C} & = & \text { Koefisien kekasaran Chezy }\left(\text { atau koefisien Manning, } \mathrm{n}=1 / \mathrm{C} \mathrm{h}^{1 / 6}\right)\end{array}$

\section{Pemodelan Sedimentasi (SED2D)}

SED2D adalah modul lanjutan setelah dilakukannya running RMA2 untuk memodelkan sebaran sedimen dan perubahan dasar sungai. Modul SED2D didasarkan pada persamaan konveksi-difusi sedimen suspensi yaitu:

$$
\frac{\partial c}{\partial t}+\bar{U} \frac{\partial c}{\partial x}+\bar{V} \frac{\partial c}{\partial y}=\frac{\partial}{\partial x}\left(D x \frac{\partial c}{\partial x}\right)+\frac{\partial}{\partial y}\left(D y \frac{\partial c}{\partial y}\right)+\alpha_{1} c+\alpha_{2}
$$

Keterangan:

$\begin{array}{lll}\mathrm{c} & = & \text { Konsentrasi }\left(\mathrm{kg} / \mathrm{m}^{3}\right) \\ \mathrm{t} & = & \text { Waktu (detik) } \\ \mathrm{U} & = & \text { Kecepatan rata-rata aliran arah } \mathrm{x}(\mathrm{m} / \text { detik }) \\ \mathrm{V}= & \text { Kecepatan rata-rata aliran arah y }(\mathrm{m} / \text { detik }) \\ \mathrm{Dx}= & \text { Koefisien difusi efektif arah } \mathrm{x}\left(\mathrm{m}^{2} / \text { detik }\right) \\ \mathrm{Dy}= & \text { Koefisien difusi efektif arah } \mathrm{y}\left(\mathrm{m}^{2} / \text { detik }\right) \\ \alpha 1, \alpha 2= & \text { Koefisien source term }\end{array}$

\section{METODE PENELITIAN}

\section{Lokasi dan Waktu Penelitian}

Lokasi penelitian dilakukan di Sungai Kahayan, Kelurahan Pahandut Seberang, Kecamatan Pahandut, Kota Palangka Raya. Lokasi pengambilan data dimulai dari hilir simpang Muara Rungan (batas hulu) hingga Hantasan Kudung (batas hilir) dengan total panjang sungai yang dikaji $\pm 4,1 \mathrm{~km}$. Waktu penelitian dilakukan selama 31 hari (744 jam) dimulai pada bulan November hingga bulan Desember tahun 2019. Sketsa alur dan kondisi lokasi penelitian pada Gambar 1 dan 2. 


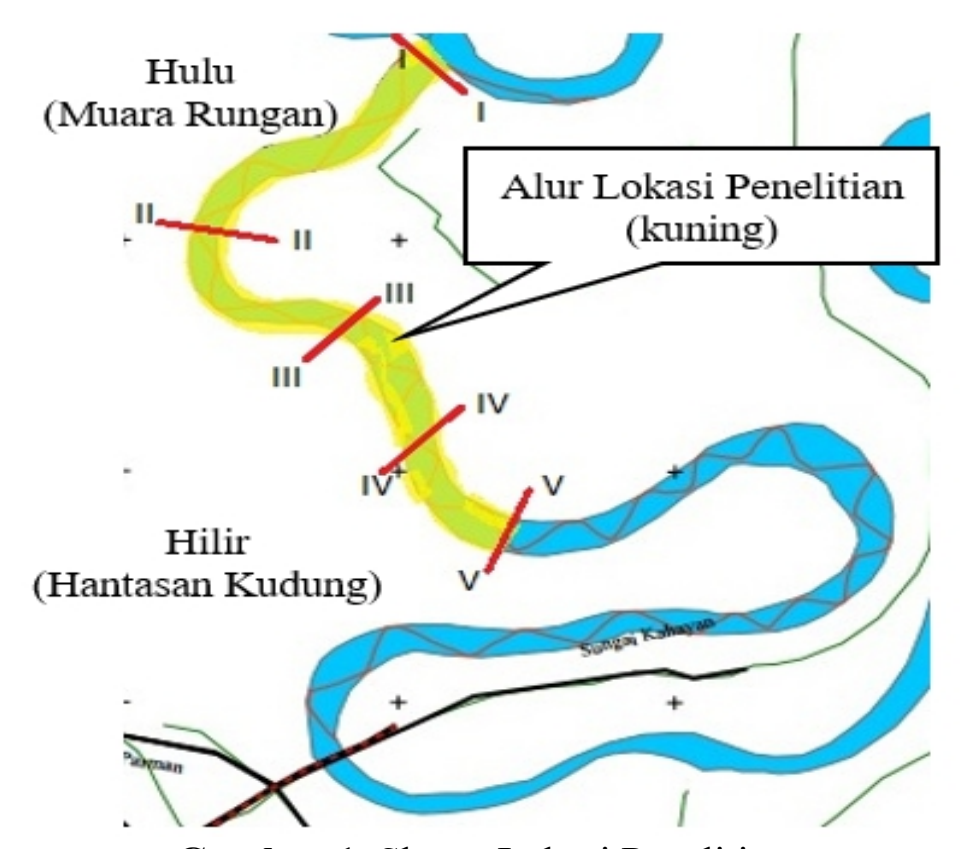

Gambar 1. Sketsa Lokasi Penelitian

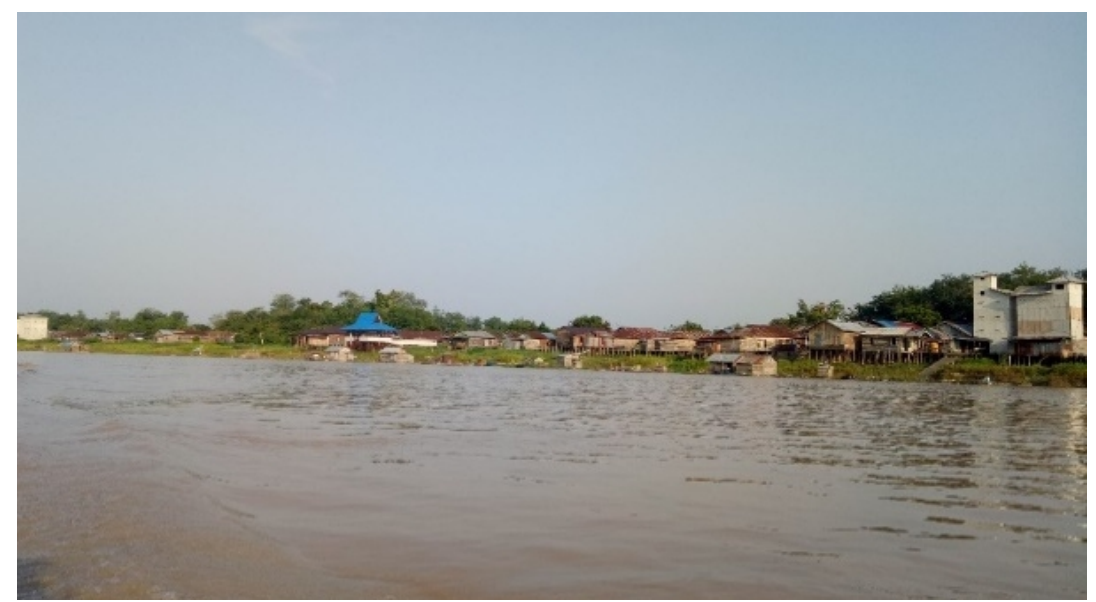

Gambar 2. Kondisi Lokasi Penelitian

\section{Tahap Penelitian}

Adapun tahapan dalam penelitian ini, yaitu:

1. Pengumpulan data dan informasi

2. Analisis data:

a. Debit aliran

b. Sedimen

c. Pemodelan arus dan sedimentasi

d. RAB pekerjaan pengerukan

3. Penyusunan laporan

\section{HASIL DAN PEMBAHASAN}

\section{Analisis Data Debit}

Perhitungan debit pada penelitian ini mengggunakan metode tampang rerata. Nilai kedalaman $\left(\mathrm{H}_{\text {air }}\right)$ yang digunakan pada perhitungan debit penampang 
menggunakan nilai kedalaman aliran penampang basah sungai yaitu dari dasar sungai hingga muka air.

Tabel 1. Hasil Perhitungan Debit

\begin{tabular}{|c|c|c|}
\hline No & Penampang & $\begin{array}{c}\text { Debit } \\
\left(\mathbf{m}^{\mathbf{3}} / \mathbf{d e t}\right)\end{array}$ \\
\hline 1 & I & 372,2049 \\
\hline 2 & II & 237,3732 \\
\hline 3 & III & 216,8836 \\
\hline 4 & IV & 224,0003 \\
\hline 5 & V & 282,0737 \\
\hline
\end{tabular}

\section{Analisis Pola Aliran Pada Modul RMA2}

Dalam pemodelan arus pada modul RMA2, diperlukan data yang digunakan sebagai kondisi batas (boundary condition) di hulu dan hilir, yaitu:

1. Debit inflow sebagai kondisi batas hulu, dan

2. Tinggi muka air yang digunakan sebagai kondisi batas hilir.

Sebelum model RMA2 dilakukan running, perlu dilakukan pengecekan data kondisi batas, Material Properties, dan Model Control untuk pengaturan simulasi.

Hasil permodelan arus pada Gambar 3 memperlihatkan bahwa kecepatan aliran yang semakin ke hilir semakin meningkat terutama pada tiap belokan cenderung terjadi perubahan kenaikan kecepatan aliran.

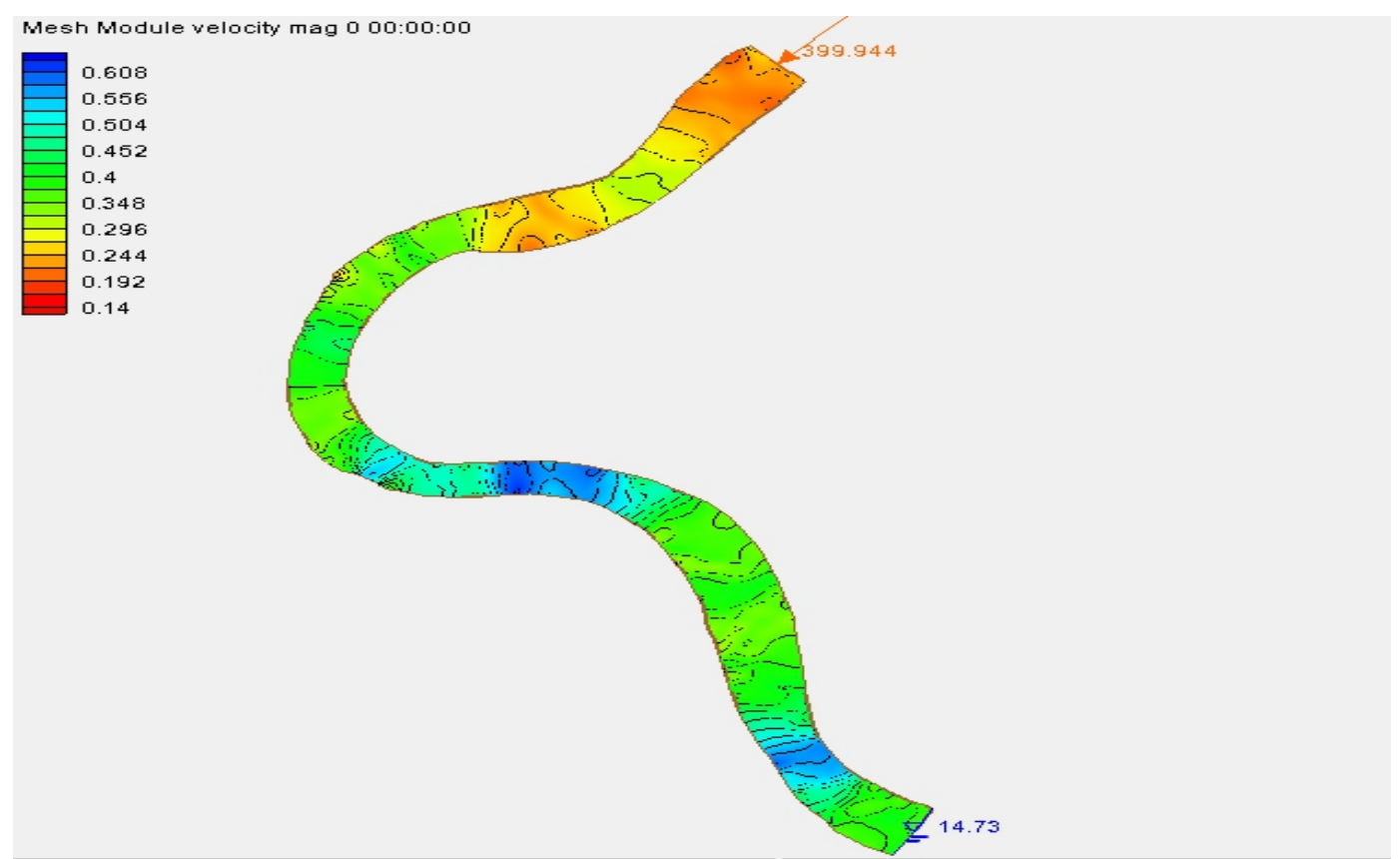

Gambar 3. Hasil Running Kecepatan Aliran Berdasarkan Warna pada Modul RMA2

Hasil permodelan arus pada Gambar 4 memperlihatkan bahwa alur sungai semakin ke hilir mengalami pendangkalan akibat terjadinya sedimentasi. 

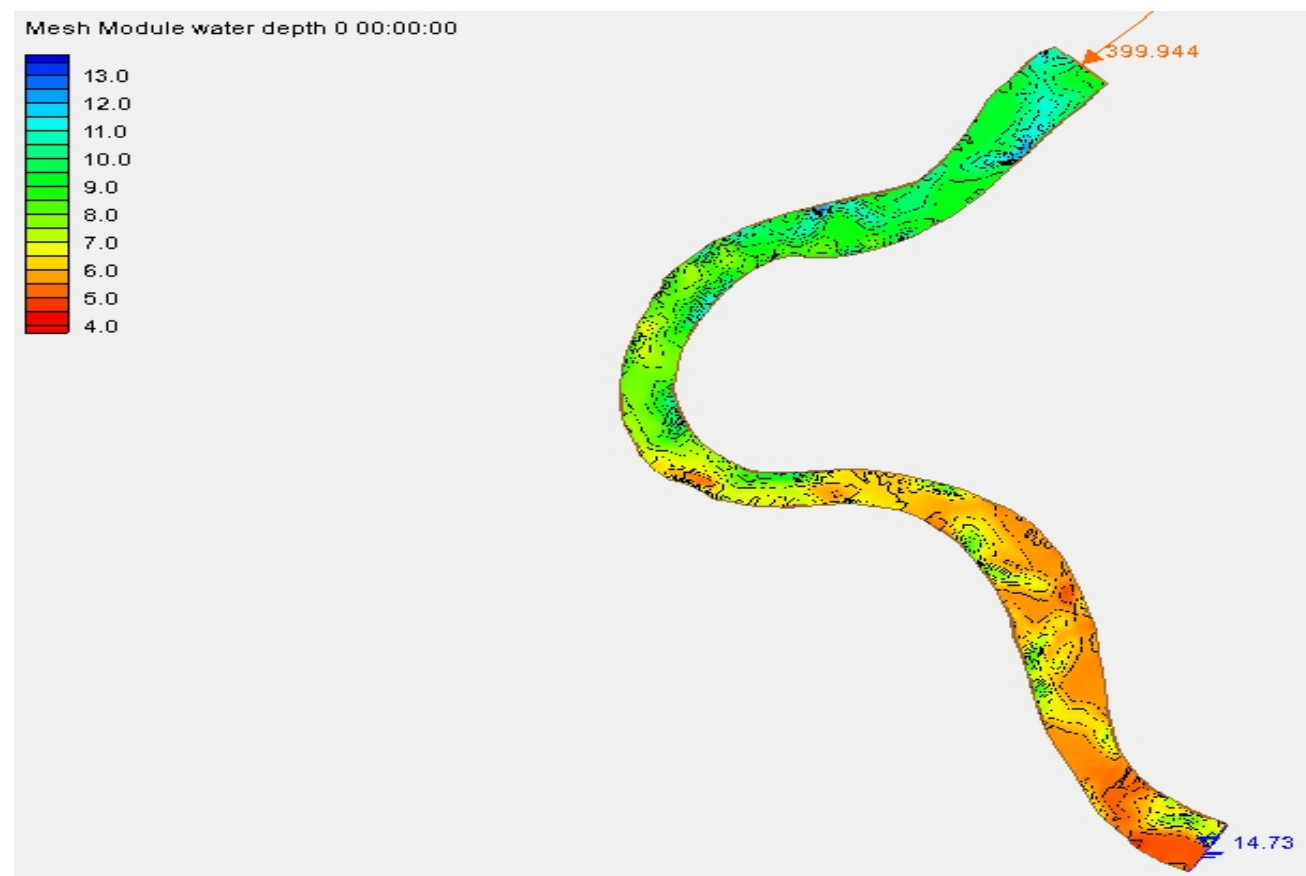

Gambar 4. Hasil Running Kedalaman Air pada Modul RMA2

Hasil permodelan arus pada Gambar 5 memperlihatkan bahwa alur sungai yang apabila semakin ke hilir maka tinggi muka air semakin menurun.

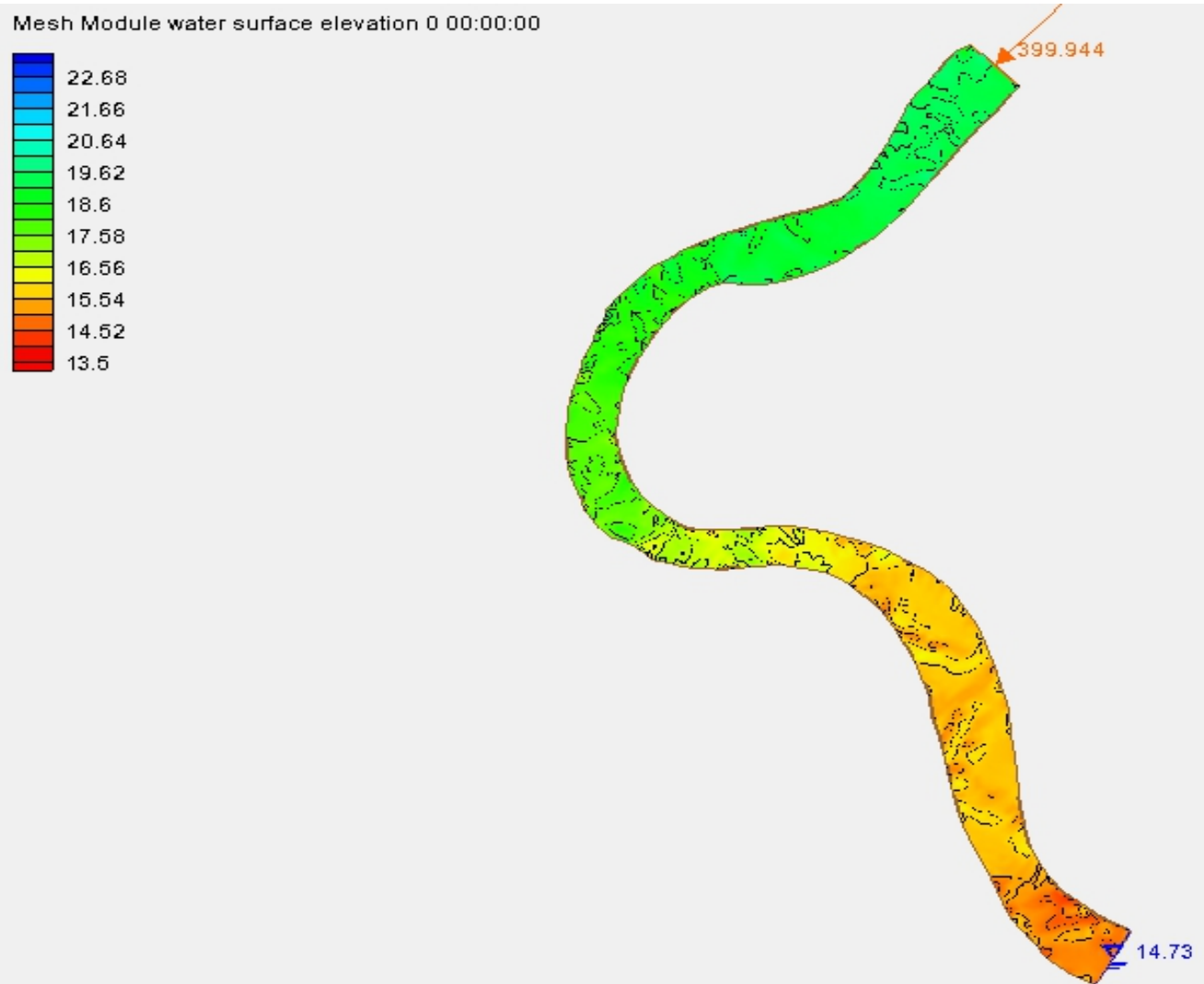

Gambar 5. Hasil Running Tinggi Muka Air pada Modul RMA2 


\section{Root Mean Square Error (RMSE)}

Setelah dilakukan proses running pemodelan pada modul RMA2, perlu dilakukan pemeriksaan tingkat kesesuaian antara pemodelan dan hasil pengukuran lapangan sebelum melanjutkan pemodelan untuk modul SED2D. Pemeriksaan tingkat kesesuaian ini menggunakan metode RMSE (Root Mean Square Error) dengan rumus:

$\operatorname{RMSE}=\sqrt{\frac{\sum_{\mathrm{i}=1}^{\mathrm{n}}\left(\mathrm{x}_{0}-\mathrm{x}_{\mathrm{c}}\right)^{2}}{\mathrm{n}}}$

Keterangan:

$\mathrm{x}_{\mathrm{O}} \quad=$ Data observasi/lapangan

$\mathrm{x}_{\mathrm{c}} \quad=$ Data hasil simulasi

$\mathrm{n} \quad=$ Jumlah data

Adanya parameter nilai Viskositas Eddy dan kekasaran Manning agar hasil simulasi pemodelan mendekati data observasi. 4 (empat) plan dengan variasi besaran Viskositas Eddy dan kekasaran Manning serta RMSE masing-masing plan dapat dilihat pada Tabel 2.

Tabel 2. Perbandingan Nilai RMSE

\begin{tabular}{|c|c|c|c|c|}
\hline \multirow{2}{*}{ Plan } & \multirow{2}{*}{$\begin{array}{c}\text { Viskositas } \\
\text { Eddy }\end{array}$} & \multirow{2}{*}{$\begin{array}{c}\text { Kekasaran } \\
\text { Manning }\end{array}$} & \multicolumn{2}{|c|}{ RMSE } \\
\cline { 4 - 5 } & & & Kecepatan & TMA \\
\hline A & 2500 & 0,033 & 0,0034 & 0,2750 \\
\hline B & 2500 & 0,04 & 0,0035 & 0,3137 \\
\hline C & 3000 & 0,033 & 0,0034 & 0,2932 \\
\hline D & 3000 & 0,04 & 0,0035 & 0,3302 \\
\hline
\end{tabular}

Dari Tabel 2 dapat disimpulkan nilai RMSE pada plan A mempunyai nilai RMSE yang lebih mendekati dengan data observasi sehingga selanjutnya nilai Viskositas Eddy dan angka kekasaran Manning pada plan A digunakan pada modul SED2D.

\section{Analisis Pola Sebaran Sedimen Pada Modul SED2D}

Pada modul SED2D perlu adanya data masukan yang digunakan sebagai syarat untuk dilakukan running yaitu data konsentrasi sedimen dan ukuran butiran pasir. Sampel sedimen diuji di laboratorium untuk mendapatkan hasil data konsentrasi sedimen yang dimasukkan sebagai data input pada modul SED2D dalam pemodelan SMS. Adapun hasil data dan pemodelan dapat dilihat pada Tabel 3 dan Gambar 6.

Tabel 3. Hasil Analisis TSS Suspended Load Sedimen

\begin{tabular}{|c|c|c|c|c|}
\hline \multirow{2}{*}{ Penampang } & \multicolumn{3}{|c|}{$\begin{array}{c}\text { Parameter yang } \\
\text { di analisis }\end{array}$} & \multirow{2}{*}{$\begin{array}{c}\text { Rata- } \\
\text { rata } \\
\text { (mg/l) }\end{array}$} \\
\cline { 2 - 4 } & \multicolumn{2}{|c|}{ TSS / Conc (mg/l) } \\
\cline { 2 - 4 } & $\begin{array}{c}\text { Rai } \\
\text { I }\end{array}$ & $\begin{array}{c}\text { Rai } \\
\text { II }\end{array}$ & $\begin{array}{c}\text { Rai } \\
\text { III }\end{array}$ & \\
\hline I & 112 & 84 & 104 & 100,000 \\
\hline II & 220 & 160 & 110 & 163,333 \\
\hline III & 204 & 202 & 126 & 177,333 \\
\hline IV & 320 & 542 & 230 & 364,000 \\
\hline V & 298 & 206 & 580 & 361,333 \\
\hline
\end{tabular}



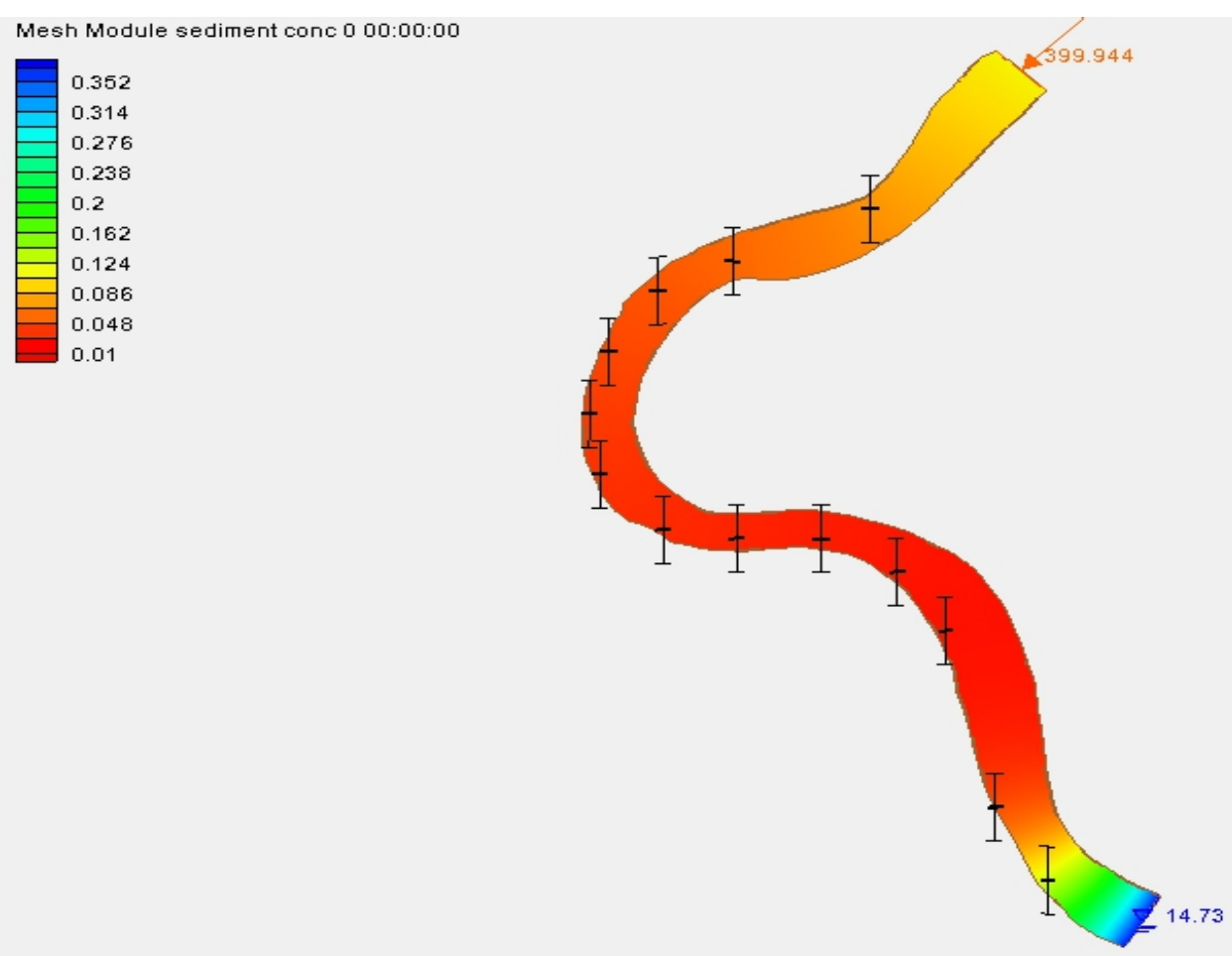

Gambar 6. Hasil Running SED2D dan Titik Pengamatan Konsentrasi Sedimen

Berdasarkan hasil running model SED2D pada Gambar 6, pada titik-titik pengamatan menunjukkan adanya penurunan nilai konsentrasi sedimen dari hulu ke hilir, namun pada penghujung bagian hilir konsentrasi cenderung naik.

\section{Pengerukan}

Data sungai baik lebar maupun kedalaman didapat dari hasil running pemodelan SMS dan perhitungan volume pengerukan dikhususkan untuk sepanjang alur penelitian. Data kedalaman dari hasil running yang digunakan merupakan kedalaman titik tengah pada tiap penampang dengan jarak antar penampang 100

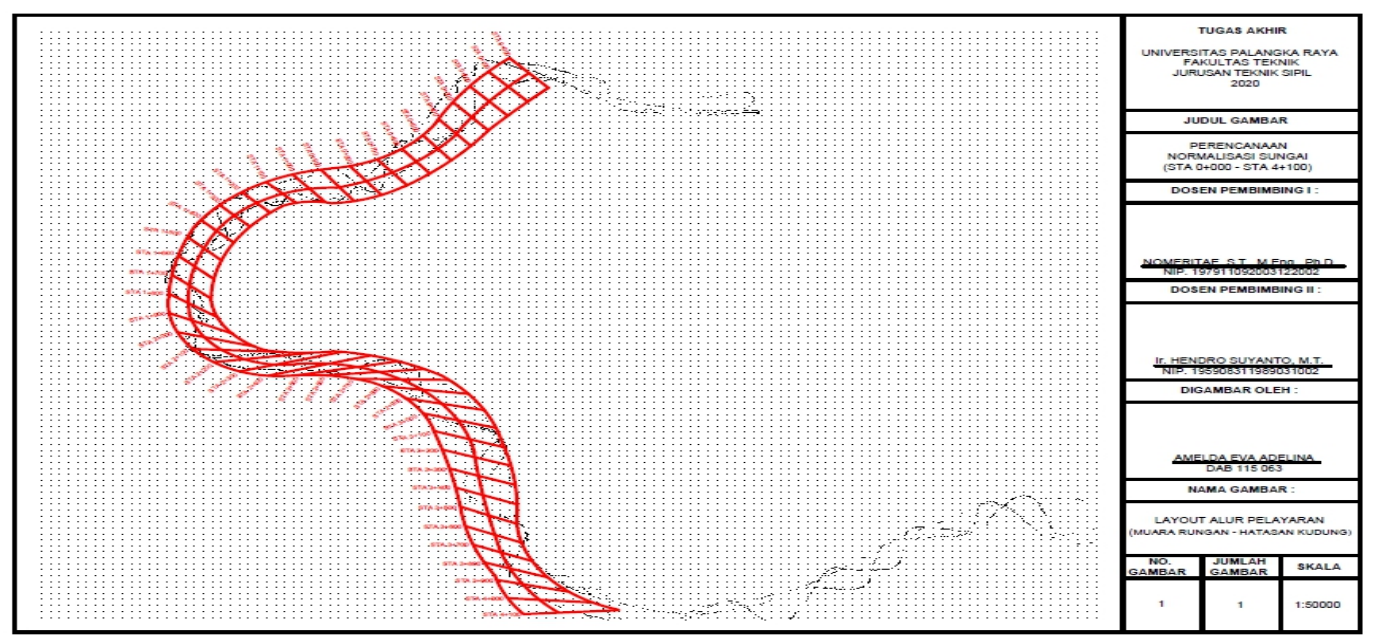

m.

Gambar 7. Layout Alur Pelayaran yang Direncanakan (STA 0+000-STA 4+100) 
Dapat dilihat layout alur pelayaran dan sketsa luas area pengerukan pada Gambar 7 dan 8.
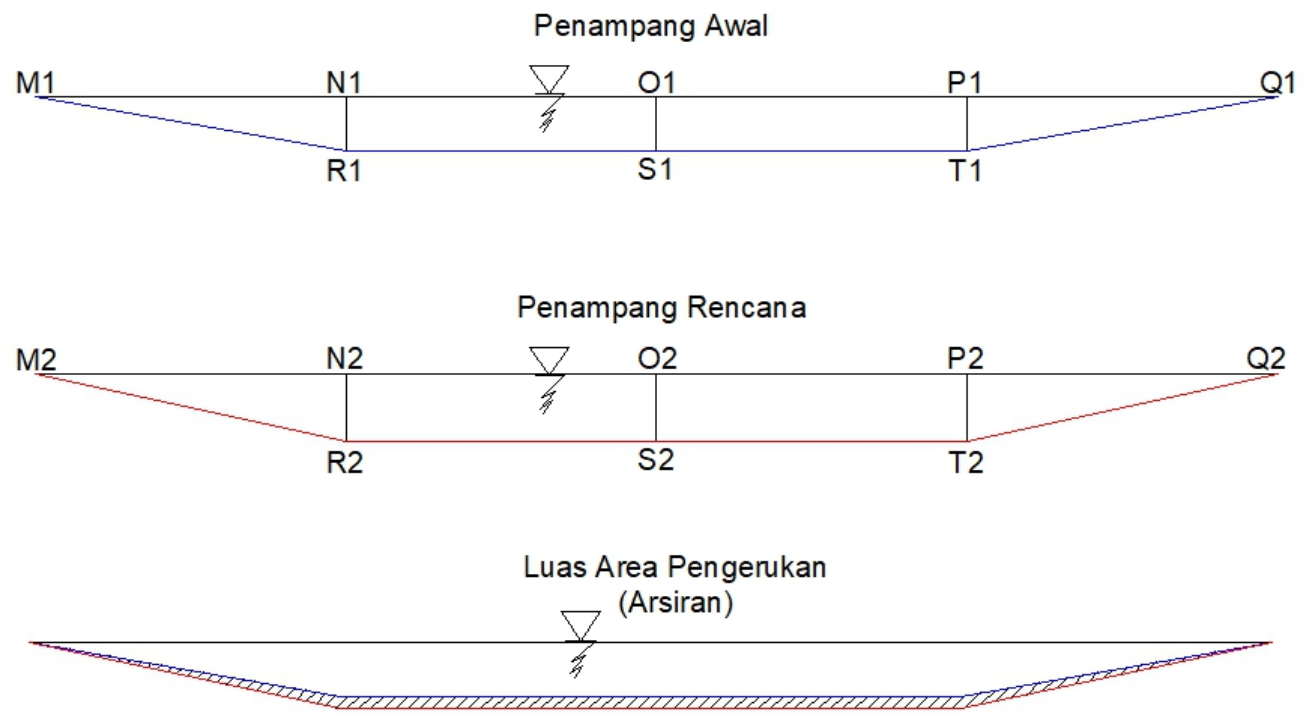

Gambar 8. Sketsa Luas Area Pengerukan

Untuk memudahkan perkiraan volume material yang akan dikeruk, alur pelayaran dibagi menjadi beberapa segmen dengan jarak antar segmen ditentukan. Perhitungan volume pengerukan dapat dihitung melalui persamaan berikut:

$\mathrm{V}=\frac{\left(\left(\mathrm{A}_{\mathrm{i}}\right)+\left(\mathrm{A}_{\mathrm{i}+1}\right)\right)}{2} \times \mathrm{l}$

Keterangan:

$\mathrm{i} \quad=$ Segmen

$\mathrm{V} \quad=$ Perkiraan volume pengerukan $\left(\mathrm{m}^{3}\right)$

A $\quad=$ Luas penampang melintang alur $\left(\mathrm{m}^{2}\right)$

$1=$ Jarak antar segmen $(\mathrm{m})$

Berdasarkan pada Persamaan 7, agar alur pelayaran dapat dilalui 3.000 DWT maka diperlukan pengerukan pada STA 0+000 - STA 4+100 di Sungai Kahayan lokasi Muara Rungan sampai Hantasan Kudung sebesar 272.405,44 m³.

\section{Rencana Anggaran Biaya}

Perhitungan rekapitulasi dikhususkan untuk pekerjaan pengerukan pada STA 0+000 sampai dengan STA 4+100 dengan volume pengerukan menggunakan hasil perhitungan. Dapat dilihat pada tabel berikut. 
Tabel 4. Rencana Anggaran Biaya (RAB)

\begin{tabular}{|c|c|c|c|c|c|c|c|}
\hline No & Uraian Pekerjaan & Satuan & Volume & \multicolumn{2}{|c|}{ Harga Satuan } & \multicolumn{2}{|c|}{ Jumlah Harga } \\
\hline 1 & 2 & 3 & 4 & & 5 & & 6 \\
\hline $\mathbf{I}$ & \multicolumn{7}{|c|}{ PEKERJAAN PERSIAPAN } \\
\hline 1 & $\begin{array}{l}\text { Mobilisasi \& } \\
\text { Demobilisasi }\end{array}$ & Ls & 1 & \multicolumn{2}{|c|}{$\operatorname{Rp} 200.000 .000,00$} & $\mathrm{Rp}$ & $200.000 .000,00$ \\
\hline 2 & $\begin{array}{l}\text { Pekerjaan Papan } \\
\text { Nama Proyek }\end{array}$ & $\mathrm{M}^{2}$ & 2 & & $482.062,75$ & $\mathrm{Rp}$ & $964.125,50$ \\
\hline 3 & $\begin{array}{l}\text { Pekerjaan } \\
\text { Pembersihan Lokasi } \\
\text { Papan Nama Proyek }\end{array}$ & $\mathrm{M}^{2}$ & 2 & $\mathrm{Rp}$ & $25.875,00$ & $\mathrm{Rp}$ & $51.750,00$ \\
\hline \multicolumn{6}{|c|}{ Jumlah Harga Pekerjaan I } & \multicolumn{2}{|c|}{ Rp 201.015.875,50 } \\
\hline II & \multicolumn{7}{|c|}{ PEKERJAAN TANAH } \\
\hline 1 & Galian Tanah & $\mathrm{M}^{3}$ & 272405,44 & $\mathrm{Rp}$ & $23.892,32$ & \multirow{2}{*}{\multicolumn{2}{|c|}{$\begin{array}{l}\text { Rp 6.508.396.802,91 } \\
\text { Rp 6.508.396.802,91 } \\
\end{array}$}} \\
\hline \multicolumn{6}{|c|}{ Jumlah Harga Pekerjaan II } & & \\
\hline & & Total H & & & & \multicolumn{2}{|c|}{ Rp 6.709.412.678,41 } \\
\hline
\end{tabular}

\section{PENUTUP}

\section{Kesimpulan}

1. Dengan model control menggunakan nilai Viskositas Eddy (E) 2500 PascalSec dan kekasaran Manning (n) 0,033, maka didapat nilai RMSE terkecil yang lebih mendekati dengan data observasi. Dari penyesuaian pemodelan tersebut didapat nilai kecepatan aliran $0,192 \mathrm{~m} /$ detik - 0,608 m/detik yang arahnya semakin ke hilir pada sisi luar tiap belokan berpotensi terjadinya gerusan.

2. Kapal barang yang direncanakan berkapasitas 3.000 DWT agar dapat beroperasi di Sungai Kahayan lokasi Muara Rungan sampai Hantasan Kudung perlu dilakukan pengerukan pada alur pelayaran dengan volume pengerukan sebesar 272.405,44 m3.

3. Estimasi anggaran biaya yang diperlukan untuk pekerjaan pengerukan normalisasi sungai untuk mendapatkan alur pelayaran yang optimal sepanjang lokasi Muara Rungan sampai Hantasan Kudung sebesar Rp.6.709.412.678,41.

\section{Saran}

1. Dalam pengumpulan data di lapangan akan lebih baik menggunakan alat yang lebih memadai agar meningkatkan keakuratan data dan mengurangi tingkat kesalahan (error) dari alat maupun petugas lapangan.

2. Perlu adanya pengamatan dan pengukuran yang berkelanjutan untuk mengetahui keakuratan data dari waktu ke waktu.

3. Dengan ukuran Sungai Kahayan yang tergolong dalam jenis sungai besar, maka akan semakin besar terjadinya gerusan dan sedimentasi sehingga perlu dilakukan penanganan dalam normalisasi sungai secara berkala.

4. Meningkatkan potensi dalam bidang perairan baik wisata, transportasi maupun bongkar muat barang untuk memajukan perekonomian daerah. 


\section{DAFTAR PUSTAKA}

1. Asdak, Chay. 2002. Hidrologi dan Pengelolaan Daerah Aliran Sungai. Yogyakarta: Gadjah Mada University Press.

2. Maryono, A. 2017. Eko-Hidraulik Pengelolaan Sungai Ramah Lingkungan. Yogyakarta: Gadjah Mada University Press.

3. Nomeritae, Saputra, R. H. 2018. Aproksimasi Potensi Penurunan Dasar Sungai Bermeander Pada Penggal Sungai Seruyan Di Desa Hanau Kecamatan Hanau Kabupaten Seruyan Provinsi Kalimantan Tengah. Makalah disajikan dalam Seminar Nasional Tahunan V, Universitas Lambung Mangkurat, Banjarmasin, 1 Desember.

4. Prabowo, C. A. A. 2017. Analisis Sedimentasi Sungai Kahayan Segmen Dermaga Tugu Sampai Muara Rungan Berdasarkan Pengukuran Batimetri di Kota Palangka Raya Provinsi Kalimantan Tengah. Tugas Akhir Jurusan Pertambangan Fakultas Teknik Universitas Palangka Raya.

5. Syamsudin, A.P., Muliati, Y., Madrapriya, F. 2017. Studi Perencanaan Alur Pelayaran Optimal Berdasarkan Hasil Pemodelan Software SMS-8.1 di Kolong Bandoeng, Belitung Timur. Jurnal Teknik Sipil, Institut Teknologi Nasional. 